\title{
NEWYYSBKHOOL
}

digitalcommons.nyls.edu

Faculty Scholarship

Articles \& Chapters

1994

\section{Assessing the Quality of Expert Testimony in Cases Involving Children}

Stephen A. Newman

Follow this and additional works at: http://digitalcommons.nyls.edu/fac_articles_chapters

\section{Recommended Citation}

22 J. Psychiatry \& L. 181 (1994)

This Article is brought to you for free and open access by the Faculty Scholarship at DigitalCommons@NYLS. It has been accepted for inclusion in Articles \& Chapters by an authorized administrator of DigitalCommons@NYLS. 


\section{HEINONLINE}

Citation: 22 J. Psychiatry \& L. 1811994

Provided by:

New York Law School<br>The Mendik Library

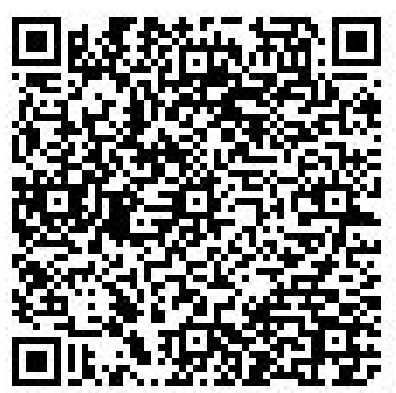

Content downloaded/printed from HeinOnline (http://heinonline.org)

Wed Mar 23 14:02:05 2016

-- Your use of this HeinOnline PDF indicates your acceptance of HeinOnline's Terms and Conditions of the license agreement available at http://heinonline.org/HOL/License

-- The search text of this PDF is generated from uncorrected OCR text.

-- To obtain permission to use this article beyond the scope of your HeinOnline license, please use:

https://www.copyright.com/ccc/basicSearch.do?

\&operation $=$ go\&search Type $=0$

\&lastSearch $=$ simple\&all=on\&titleOrStdNo=0093-1853 


\section{Assessing the quality of expert testimony in cases involving children}

BY STEPHEN A. NEWMAN, J.D.

Mental health experts must be held to a high standard of quality when presenting opinions in legal cases involving children. This article sets forth a number of suggestions for judges, lawyers, and mental health professionals themselves to consider in preparing, scrutinizing, and judging the quality of forensic reports and testimony. The many piffalls of forensic work need to be understood if such expertise is to be given its proper weight in these cases.

Forty-five years ago, in Courts on Trial, Judge Jerome Frank identified the essential difficulty of factfinding when he titled one chapter of his book "Facts Are Guesses." Disputed facts must be guessed at, using the array of aids common to the courtroom: physical evidence, documents, demonstrations, lay witnesses of varying degrees of probity and accuracy, and experts. For courts to do justice, Frank observed, they must not only come up with the right legal rule, they must also make the correct findings of fact. Because Frank saw numer- 
ous flaws in the factfinding process, he feared that too often justice was not rendered in adjudicated cases.

In cases involving children, the integrity of the factfinding process is crucial. Modern cases in family and divorce courts often feature drastic allegations of child sexual abuse, of physical cruelty, of parental indifference and neglect. Decisions of lasting consequence regularly turn on the facts found by the court.

Reports and testimony from specialists in the social sciences play an increasing and sometimes dominant ${ }^{2}$ role in these cases. But however confidently they speak, these experts too are only guessing at the facts. Judge David L. Bazelon, a jurist well known for his efforts to make law responsive to the insights offered by psychology, once told an audience of psychiatrists:

The "educated guess" that psychiatrists provide-and it is only an educated guess-is only as good as the investigation, the facts, and the reasoning that underlies it. ${ }^{3}$

When the social science expert enters the legal arena, lawyers and judges may be tempted to simply defer, trusting in the expert's greater knowledge of psychology, human relationships, and children. But Judge Bazelon's echo of Judge Frank's remark about facts-as-guesses cautions against uncritical deference.

Indeed, when experts offer their educated guesses, their opinions must be assessed as carefully as the testimony of other witnesses, but with certain unique considerations in mind. This article sets forth various criteria for making an assessment of the quality of this evidence. By sometimes highlighting the pitfalls of expert testimony, I do not mean to deny its importance in family cases. Indeed, it is sometimes the case that vital information about a child can be elicited only outside the courtroom, in the settings and conditions provided by the mental health profession. ${ }^{4}$ And mental health profession- 
als are uniquely situated to supply empirical data, explain research studies, and assist in the application of the available knowledge from psychology to the case at hand.

Their importance makes it all the more imperative that mental health experts be held to a high standard of quality when presenting opinions and recommendations in court. This in turn requires informed cross-examination by lawyers (something not always done well in these cases ${ }^{5}$ ) and judicial awareness of the virtues and pitfalls of this type of testimony.

Legal professionals must avoid the conclusion that what the expert offers is purely "scientific." Clinical opinion-the form of expertise most often heard in family cases-is a blend of many things: expert knowledge, theoretical preferences, beliefs derived from the expert's unique set of past clinical cases, inferences and interpretations drawn from interviews with and observations of the principal actors in the case, predictions of future behavior, and individual character, values, intuition and judgment. It is subject to many limitations, both professional and personal, discussed in more detail throughout this article. The quality of an opinion is highly dependent upon the knowledge and skill of the individual evaluator; in the words of two commentators, "the clinician himself-his ability to observe, to interact, to feel, and to sense intuitively-becomes the chief instrument" in the clinical search for truth.

It is well to remember that even in the modern age, the ideal decision maker in family matters is not the scientist, but the wise man. It is not the knowledge of an Einstein or a Freud that we desire in the most troublesome cases, but the wisdom of a Solomon. With this in mind, I offer the following cautions, caveats, and criteria for the assessment of the quality of expert testimony in legal cases involving children. 


\section{Competence}

The expert's In court, competence is usually measured by reference to the level of expert's credentials. Credentials are a kind of shorthand for general experts with the judgment, intelligence, and training to percompetence form the necessary professional tasks, to explain the state of knowledge that exists, and to extrapolate reasonably from that knowledge. Psychiatrists, psychologists, and social workers, the usual experts appearing in family matters, are identified by their educational degrees, licenses, depth of training, and years of experience. ${ }^{7}$

Credentials sometimes confer undeserved respectability. The field of psychology has spawned various experts whose claim to expertise is questioned by other mental health professionals. Marian Hall, former director of psychology at Minneapolis Children's Medical Center, decries a "cottage industry" of

so-called professionals [specializing in child sexual abuse] who are employed by public agencies or available for hire by private parties in divorce and custody disputes and who have little or no specialized training in child development, child assessment, mental health, or human sexuality. Too frequently, their weekend workshops and seminars have focused on frenzied approaches and altruistic intentions about what is best for the child. ${ }^{8}$

Hall goes on to describe the weekend workshops and seminars certain activist mental health professionals attend-no doubt cited to courts as impressive evidence of their expertise and training-as misguided, scientifically worthless efforts.

Professional experience is often used as a yardstick in assessing the competence of an expert. But experience is not necessarily a good marker for competence. Testimony of poor quality in child sex abuse cases often is delivered by socalled "validators" who appear to be qualified because of experience. One New York Family Court judge has written:

I am concerned by the proliferation of unqualified "validators," many of whom possess no more than marginal scientific and educa- 
tional credentials necessary for qualification as an expert, but who are able to bootstrap their evaluations by reciting the number of validations they have done and the number of times they have been qualified as expert witnesses in other cases. Routinely, the quality of the prior evaluations is not examined, and many of the prior evaluations were without objection or adequate examination of the expert's credentials. ${ }^{9}$

These problems are compounded by the fact that many clinical experts never obtain feedback on how their prior recommendations have fared. Without feedback, there is no opportunity to learn from one's early mistakes, or even to know if what one is doing is scientifically valid. ${ }^{10}$ Indeed, some experts may simply repeat their errors over and over again for years-and then claim to be experienced. Whether clinicians with years of experience ever get any feedback in the course of their work ought to be a routine question in court proceedings involving children.

Did the Even well-credentialed experts go astray in particular cases. expert do a An unfortunate example was set by Dr. Marshall Schecter, a competent distinguished emeritus professor of child psychiatry at the job in this University of Pennsylvania, when he testified in the Baby particular $M{ }^{11}$ case. Schecter claimed that Mary Beth Whitehead was case? not a good mother for her baby because she didn't play the right way with her infant. He criticized this mother for choosing to play with stuffed animals instead of pots and pans. His views on this, and on the psychologically correct way to play "patty-cake," made him the subject of a very amusing, and devastating, column by New York Times critic Russell Baker, which Baker entitled "Mom Flunks Patty-Cake." 12 Schecter, despite his impeccable credentials, had for some reason delivered testimony that sounded absurd.

Another pitfall for the competent expert is the temptation to stray beyond one's competence. When their own expertise runs out, instead of keeping quiet, some experts boldly proceed to offer testimony in a realm that they have not ade- 
quately practiced or studied. Legal professionals must be sensitive to the boundaries of expertise if they are to rein in the wandering expert.

\section{Thoroughness of the expert's evaluation}

Was the time Experts sometimes fail to devote adequate time to forensic devoted to evaluations. This is not due simply to incompetence. Experts the clinical evaluation adequate?

are busy, workloads are heavy, and other time demands intrude. Those pressed for time may cut corners in various ways: by relying on information from records rather than conducting personal interviews, by speaking briefly to key people on the phone, by neglecting sources of information that would be tapped were there more time, and by ending inquiries prematurely. Lawyers should be alert to pick up indications of these practices in the expert's own reports, and to ask about sources of information that might have been consulted if the expert had had more time..$^{13}$

Sometimes courts (or attorneys) will not pay for an adequate evaluation. A court may limit fees unreasonably, making it difficult for any expert to do a proper job. Attorneys hiring experts may also seek a low-cost evaluation. Experts need to be prepared to educate their legal clients as to the time demands of evaluations, and to turn down cases that are doomed because of inadequate reimbursement arrangements.

While there is no fixed time for performing such tasks as a child custody evaluation or a sexual abuse inquiry, some mental health professionals have offered rough temporal guidelines. For child custody evaluations, Dianne Skafte, a private therapist and custody evaluator, suggests a time investment of approximately 16 hours for a family of two parents and one child, with an added two hours for each additional child. ${ }^{14}$ For sexual abuse evaluations, Anne H. Meltzer and April Kuchuk present a protocol that incorporates suggestions from various professional organizations. ${ }^{\text {is }}$ It calls for 
a minimum of two interviews with the child, "with an average range of two to six interviews. The length of individual interviews can vary from 30 minutes to two hours, depending upon the child's tolerance." Additional sources of information are suggested (e.g., review of records, interview with parent and caregiver), but no time limits are given in the protocol for them.

Brief evaluations leave wide gaps in knowledge, overemphasize first impressions, and produce poorly substantiated conclusions.

Were the Dr. Alan Levy warns of a "snapshot effect,"16 in which the interviews expert, in a brief look at the family, or even a look that is conducted adequate in terms of hours spent but is not spread out over over too time, is misled by atypical behavior or only temporarily compressed impaired psychological functioning. This effect, which Levy a time feels "contaminates and threatens to distort many custody period? evaluations," leads the evaluator to draw conclusions based upon evidence from moods, behavior and psychological states that later change, especially as the individual's high level of stress and anxiety in the midst of litigation diminishes over time.

Levy describes how the tension of a custody battle can lead parents to behave atypically badly or well in the evaluation process:

As their anxiety increases, parents may lie, become provocative and insulting, or even appear close to psychosis. On the other hand, some parents handle the anxiety with denial and seem to be reasonable or calm. ${ }^{17}$

The expert who sees only a "snapshot" of behavior may reach inaccurate conclusions about the subject's normal functioning. Lawyers should be alert to the possibility that the expert saw atypical behavior on the particular occasion of the evaluative interview. Nervousness and anxiety may peak at the interview itself, since it is a critical moment in the litigant's 
life; this agitated state may cause him to act in ways that negatively affect the expert's conclusions. ${ }^{18}$

Was all Evaluators must spend sufficient time, and spend it wisely. appropriate Reports and testimony should routinely inventory all of the information expert's efforts: who was interviewed, for how long, what considered? records and documents were examined, what tests or other materials were employed.

To make a child custody recommendation, the evaluator should see the children and each parent alone and together in various combinations. ${ }^{19}$ Housekeepers, teachers ${ }^{20}$ and others regularly in contact with the children are potentially good additional sources of information. Often evaluators are urged by the parties to see friends, relatives, and other supporters, but experienced evaluators rarely find these collateral sources of real value. ${ }^{21}$

The importance of a thorough, well planned evaluation is illustrated by Matter of $E l i,{ }^{22}$ a child sexual abuse case in which four mental health experts testified. The court found most reliable Dr. April Kuchuk, who, in her role as courtappointed psychologist, saw the mother alone twice, the father alone twice, the child alone three times, the child with the mother at the mother's home once, and the child with the father once in her office and once at the father's home. She also interviewed the child's babysitter and telephoned the father's therapists, the child's therapist, and the law guardian. Her solid information base, as well as her persuasive reasoning and expert knowledge of the literature in the field, impressed the court.

In sharp contrast is the expertise offered in Matter of $C / R$ Children. ${ }^{23}$ A psychologist offered his conclusion that a teenage child's depression and symptoms of mental disturbance stemmed from sexual abuse. But at trial it became clear that the expert had been entirely unaware of the girl's history of lifelong emotional disturbance. His conclusion was based 
upon the demonstrably false premise that the child's emotional problems started after the alleged time of abuse. After dissecting the expert's sloppy investigation, the court rejected what it aptly termed "an opinion offered too casually by one lacking a sufficiently thorough knowledge of the subject child's psychological condition and history. . . ."

At times, attorneys in custody cases prevent thorough inquiries by experts, by denying access to their clients (or to children in their clients' care). An expert is justified in providing information on only one parent in the dispute, but professional ethics codes do require acknowledgment of the lack of contact with the other parent. Experts need not feel obliged to offer an opinion about the ultimate issue in the case; testimony is admissible if it supplies the trier of fact with some useful information that is relevant to the ultimate issue.

\section{Use of metaphors}

Experts use metaphors and similes as a way to describe psychological concepts in terms understandable to laypersons. Metaphors in court can be vivid, memorable, and persuasive. But they can also be misleading. A metaphor highlights the ways in which one thing is like another, but it masks the differences between the two. Metaphors also tend to oversimplify the complex psychological concepts they purport to represent.

An example of a questionable psychological metaphor occurred in a rape prosecution in Pennsylvania..$^{24} \mathrm{Dr}$. Ann Burgess, testifying about rape trauma syndrome, attempted to explain how a rape victim might be able to identify her attacker after the passage of four years through flashbacks of the attack. In describing this flashback phenomenon, Burgess testified that "you [could] think of the mind like a computer button" that, when "pressed" by something in the environment, brings back the "image." This metaphor, equating the 
human mind and memory with the computer's system for retrieval of information, oversimplifies the complexity of human memory. It hides the differences between computer retrieval of data previously entered, commonly experienced to be perfectly accurate when the right buttons are pushed, and fallible human memory, which is subject to such problems as suggestibility and diminishing recall over time. The expert's metaphor constituted too strong an endorsement of the victim's ability to make the identifications that she did; the defendant's conviction was reversed.

In the much publicized "Baby Jessica" custody litigation, ${ }^{25}$ an expert psychologist testified to the devastating effect that removing a two-year-old child from the only caretakers she had ever known would have on the child's psychological well-being. At one point in the testimony, the expert provided a metaphor to explain this effect:

It's like if you think of a house: The foundation, the frame of the house, is the first thing you build. You dig a hole and you put down the cement and you put up the frame. And then you cover it up with walls, and windows and doors, and decorations. And these decorations will vary depending on the people. And when you look at the house the only thing you'll see will be the decorations and the windows. And you won't know the nature of the foundation until a storm comes. And it's only whether or not it can weather the storm that will tell you how strong the foundation is.

She now has-it's the foundation that she's building up with these primary [caretakers]. . . . ${ }^{26}$

Even in a case like this, in which the psychological testimony about harm to the child is convincing, there is reason to be cautious about the particular metaphor chosen here. The foundation of a house is finished early in the house's construction. Thereafter it is not affected by subsequent work done to create items such as windows and decorations. The metaphor suggests that the fundamental work of human personality development is completely "finished" in the first years of life, and further, that human development, at least in 
its fundamental aspects, is not affected by life events that occur subsequent to the early first years. It is not clear from the metaphor that the expert wishes to make these assertions, or whether he believes the metaphor, so interpreted, makes too strong a claim about the inflexibility of psychological developmental processes. These implications should have been explored by counsel, to establish the limits-as well as the truth - of the metaphor.

\section{Theoretical orientation}

Expert witnesses make choices about which psychological theories and techniques to believe in and practice. ${ }^{27}$ Since theoretical orientation and beliefs vitally influence experts' recommendations, they should be scrutinized. ${ }^{28} \mathrm{~A}$ striking example of reliance on theory that contributed to judicial rejection of expert testimony occurred in Matter of Eli, when a social worker's psychoanalytic orientation led her to give "considerable weight to symbolism and the child's play with certain dolls, including a bear with a long nose . . . which nose she saw as a phallic symbol." The judge regarded this interpretation as dubious and did not credit this testimony.

In custody cases, it is especially important that lawyers probe for the theories of the evaluator. One psychiatric evaluator has written that homosexuality is a mental disorder, ${ }^{29}$ disagreeing with other professional opinion on this point. This theoretical belief-and the fact that it is rejected by many, if not most, within the professional community ${ }^{30}$-obviously must be uncovered in any proceeding involving a homosexual parent.

Consider another professional controversy, centering on the question of whether there should be a preference for matching the gender of a parent and a child in custody matters. One psychiatrist, after setting out the various arguments supporting placement with the same-sex parent, says we don't know 
which deprivation-of modeling and identification with the same-sex parent or of learning how to deal with the oppositesex parent-is more serious. ${ }^{31}$ Experts in custody cases should be questioned about their views on this point, especially in light of the legal system's reluctance to base awards on gender. ${ }^{32}$

Perhaps the best-known expert trio in family law is Goldstein, Freud and Solnit, authors of the classic work Beyond the Best Interest of the Child. The book has had much beneficial influence on the law, but some of these authors' theories have been attacked by others in the field. Critics have said Goldstein, Freud and Solnit placed too much emphasis on a child's single psychological parent, failing to recognize the psychological importance of both parents to many children..$^{33}$ And their notion that courts should not order visitation, but instead allow the custodial parent to determine whether and when visitation with the non-custodial parent should take place, has been universally rejected by the courts and criticized in the mental health literature. ${ }^{34}$

While the ordinary custody case is regarded as a multifactored inquiry into the child's best interests, custody experts differ on which factors deserve highest priority. Goldstein, Freud and Solnit placed maximum emphasis on continuity of psychological ties. Others make such continuity a factor, but not necessarily an overriding factor. ${ }^{35}$ The authors of one custody text state their theoretical preference for these qualities in a child's custodian: (1) the capacity to nurture and empathize; (2) the ability to self-scrutinize; and (3) the ability to value the other parent. ${ }^{36}$ It is readily apparent that in certain cases, what an expert recommends will depend upon his theoretical views.

The latest group of experts coming to the attention of the legal community are "recovered-memory therapists," who theorize that childhood sexual abuse is the source of their patients' problems. Patients who can't recall such abuse are 
assumed to be repressing the memory of it and may be treated with such questionable techniques as the administration of "truth serum" drugs like sodium amytal. ${ }^{37}$ One psychiatrist expressed the view that

the main reason for the growth of false charges of abuse has been the recent proliferation of abuse specialists and therapists, many of whom lack any knowledge of mental illness or the workings of memory. These specialists believe fervently that many of the difficulties experienced by the people who consult them are due to sexual abuse that, if it isn't remembered, can be jogged into memory by various recovery techniques. ${ }^{38}$

Newspaper accounts ${ }^{39}$ have given warning to the legal profession about these theorists, but lawyers cannot rely upon this haphazard way of receiving information. All experts' theoretical preferences should be uncovered in the legal process and reviewed for general acceptance within the profession, and for elements that may be disputed and controversial within the profession. Ideally, alternative theories that might generate different opinions about the case at hand should be brought to the attention of the court.

\section{Syndrome testimony}

Syndrome testimony in child sexual abuse cases has become so commonplace that a cautionary word about it is in order here.

In the prosecution of day care teacher Kelly Michaels, ${ }^{40}$ expert witness Eileen Treacy, possessing a master's degree in psychology and clinical experience with child sex abuse victims, presented testimony about the "Child Sex Abuse Syndrome." 41 She identified 32 child behaviors that were supposed to indicate sexual abuse, including eating disorders, sleep problems, regression, development of fears, and sexual symptoms. Five to 15 of these behaviors, she claimed, would likely be found in an abused child. In addition, the abused 
child would likely go through most or all of these phases: (1) engagement, where the abuser gains the friendship and affection of the child; (2) sexual interaction with the abuser; (3) secrecy, in which the abuser threatens or cajoles the child to keep the secret; (4) disclosure; (5) suppression, in which the child copes with the abuse by such psychological measures as denying, avoiding, or rationalizing it. ${ }^{42}$

Judicial doubts about the validity of this syndrome testimony stemmed from Treacy's own admissions about the limitations of the theory and from the testimony of other experts who flatly rejected its validity. Treacy admitted that (1) some of the behavioral symptoms on her list could be caused by other events; (2) the psychiatric profession's authoritative reference work, the Diagnostic and Statistical Manual, did not recognize the syndrome; and (3) nearly all of the behaviors she cited were common to all types of traumatic stress.

Two experts for the defense testified that the 32 indicators of sexual abuse were too general and vague to be accurate indicators of sexual abuse (one claimed it had no other source than Treacy herself and had no validity); that the five-phase hypothesis was a model that had not been tested; and that the model was in any event a therapeutic tool for clinical treatment, not a diagnostic tool.

The court agreed that syndrome evidence "is not probative of sexual abuse. The syndrome assumes the presence of sexual abuse and only seeks to explain the child's reaction to it." Allowing Treacy to go beyond explaining that delays in reporting or recantations by children are common in abused children was deemed error in this criminal trial. ${ }^{43}$

Professor Robert Levy traces some of the difficulty with this syndrome to limitations on the influential original paper by Dr. Roland Summit, a California psychiatrist who formulated the "child sexual abuse accommodation syndrome." In Levy's words: 
Dr. Summit's article provided impressionistic, clinical findings but no data of any kind. Summit did not compare the proven cases of child sexual abuse in which the syndrome was observed with proven cases in which the syndrome was not observed. Nor did he provide any information about unproven allegation cases or cases involving false allegations in which the child nonetheless exhibited some or all symptoms of the syndrome. In short, Summit provided no information from which an informed judgment could be made as to whether symptoms of the "syndrome" might validly be considered determinative or even corroborative of sexual abuse.4

In 1992 Dr. Summit published a fascinating account of how his original paper proposing and describing the syndrome had been misused by lawyers. ${ }^{45} \mathrm{He}$ condemned both "false claims advanced by prosecutors" and the "effort by defense interests to strip the paper of any worth or relevance."46 Summit explained that his syndrome was "a clinical opinion, not a scientific instrument." ${ }^{" 47}$ It did not identify an illness or disorder but rather attempted to set forth "the responses of normal children to sexual assault." His original paper made no claim that the CSAAS was a diagnostic tool to determine the factual question of whether a child really was abused:

The words identification, detection, diagnosis, symptom, disorder, illness and pathology, which might infer a diagnostic focus, do not appear in the paper, nor is there a promise of verifying the alleged abuse with such words as test, validate, evaluate, confirm, or prove. ... The CSAAS is meaningless in court discussion unless there has been a disputed disclosure, and in that instance the ultimate issue of truth is the sole responsibility of the trier of fact. The CSAAS acknowledges that there is no clinical method available to distinguish "valid" claims from "those that should be treated as fantasy or deception," and it gives no guidelines for discrimination.

The CSAAS is used appropriately in court testimony not to prove a child was molested but to rebut the myths which prejudice endorsement of delayed or inconsistent disclosure. ${ }^{48}$

Some judges, however, perhaps misled by testifying experts, persist in calling the syndrome an accepted diagnosis. ${ }^{49}$ And courts in child protective proceedings sometimes allow this testimony to be used to help prove abuse occurred, even if 
they reject such evidence in criminal cases. ${ }^{50}$ But admitting it still leaves open the question of its value.

Not only lawyers, but mental health experts as well, are guilty of exaggerating the significance of the syndrome. One common way experts attempt to enhance the effect of their syndrome testimony is to state that the behavior observed in the child is "consistent with" sexual abuse. This locution is too often used to supply by implication an answer to the crucial question of causation. If the behavior is consistent with sex abuse, the implication is that sex abuse probably caused the behavior. But a claim that the behavior is "consistent with" the sex abuse syndrome does not reveal causes for the behavior other than sex abuse that may exist. The symptom of headache is consistent with being hit over the head with a blunt instrument, but blunt instruments do not cause most people's headaches.

If "consistent with" testimony is given, judges need to ask what else the behavior might be "consistent with." Experts offering to provide the causation probabilities associated with the different causative possibilities are attempting to resolve the ultimate issue for the court and are going beyond what their science can support. ${ }^{\text {st }}$

Summit cites this type of testimony as a misuse of the CSAAS. He notes that "a child's . . . silence might be said to be consistent with the CSAAS, as if not complaining proves the complaint." ${ }^{2}$ Silence, of course, also is consistent with no abuse. What the CSAAS does show is that silence doesn't rule out abuse, since some abused children do stay silent because of threats, fear they won't be believed, etc.

What is the future of syndrome testimony? Marian Hall suggests that we can expect mental health professionals to move away from syndromes and lists of typical symptoms. She explains: 
With the increasing quantity and sophistication of our research it is becoming more clear that "syndromes" and "profiles," typical courses, effects, and dynamics do not exist, that in fact, patterns of child abuse cannot be fit into simple or generalized categories and must be studied, at least for purposes of legal reporting, on a caseby-case basis..$^{53}$

Hall expects that ongoing work by researchers will produce theories that explain the psychological effects of abuse in more sophisticated terms, commensurate with the complexities of child development. Sexual abuse will be seen not merely as producing a standard set of symptoms, but as a traumatic interference with the child's developing self-image, developing sexuality, developing sense of control, and developing sense of trust in relationships. ${ }^{54}$

This leaves today's courts working with some experts using an oversimplified model of sex abuse symptomology. Nevertheless, experts familiar with the syndrome literature and able to go beyond it can be helpful. First, they can dispel the myths about abuse that Summit wrote about (e.g., the myth that delay in reporting always proves that the child's original report of abuse was false). Second, they can report on the emerging research on children's memory, communication capacities, cognitive abilities, and ability to distinguish fantasy from reality. ${ }^{5 s}$ This may help courts struggling with testimony which in some respects is credible and in some not, such as occurred in a federal court that heard credible testimony about sex abuse mixed with statements about a dog driving the young victim to a safe place in a police car. ${ }^{56}$ Finally, stripped of the syndrome terminology, much expert testimony offered in sex abuse cases consists of standard clinical observations and insights that if properly supported, contribute to and help clarify the overall picture ultimately created by all the testimony. ${ }^{57}$ 


\section{Evaluative techniques: the use of anatomically correct dolls}

Play therapy is "an established technique for obtaining information about the feelings and problems of young children." Psychologist Marian Hall writes:

Reconstructive cues such as puppets, family dolls, drawing materials, and doll house equipment may be useful memory aids for young children. The supportive nature of nonverbal aids, and especially the open-ended, nonsuggestive nature of most play materials, makes the information gathered in such sessions especially valuable. $^{59}$

One kind of toy-the anatomically correct doll-has generated intense controversy, however. Some courts ${ }^{60}$ and commentators would treat them as inadmissible. Professor Robert J. Levy, reviewing the literature on dolls in a 1989 article, ${ }^{61}$ claims that the few empirical studies supporting the use of dolls "are shallow as well as narrow." Using small sample sizes, and failing to study the reactions to these dolls of children who have not been sexually abused, the studies, says Levy, draw unjustified conclusions about what can be learned from the doll play. He complains that the dolls are not standardized. Two prosecutors are quoted as saying:

Dolls from different manufacturers may look quite different from each other. Some dolls have a look children find friendly, while others may appear menacing. Some dolls are completely out of scale, with disproportionately large sexual parts. The same is true in the child-adult size ratio. Some dolls are so bizarre looking that their use may unintentionally add humor to the case.

In the prosecution of Kelly Michaels, a New Jersey appellate court expressed skepticism about the way in which dolls were used in that case:

Anatomical dolls were used in the interviews, and in some cases the children did not disclose anything until they were either presented with the dolls, shown various eating utensils, or encouraged to demonstrate how Kelly might have hurt a little boy or girl. The records of the interviews show that these methods caused certain 
children to use their imagination and stray from reality, even to the dismay of the investigator at times. ${ }^{62}$

The court went on to cite the "Manual of the National Center for Prosecution of Child Abuse," whose guidelines indicate the dolls "may not be appropriate in all instances, and that careful attention should be paid to the methods employed when they are used."

The dolls need not, however, be thought of as a scientific test requiring empirical validation. In the words of a Michigan appeals court, they "are a tool to permit children to communicate ideas which they are unable to express verbally because they are too young or anxiety-ridden or because they lack the vocabulary." 63 Experts who use the dolls must be aware of their potential to stimulate fantasy play, but the dolls may also be used to demonstrate real experiences of sexual abuse. This causes some experts to reject the notion that doll play is always inherently unreliable. ${ }^{64}$

While anatomically correct dolls are generally suggestive of sexuality, what a particular child does or says about them may not be suggested by their mere presence. Nelson v. Farrey ${ }^{65}$ provides an example. Nelson was convicted in a Wisconsin state court of molesting his three-year-old daughter. Following the conviction, he sought habeas corpus relief in federal court. The evidence included the child's hearsay statements, related to the court by Dr. Donald McLean, a clinical psychologist who did extensive therapy with the child. In one session, the child put a male and a female doll, both anatomically complete, in a position simulating fellatio. The girl then said that the female got "mud on her face" that was "white and sticky." The court acknowledged the general risk that dolls with sexual parts might elicit "fantasy and not recall" but noted that "[m]erely playing with anatomically correct dolls would not have given her the idea that one might be sprayed with 'white mud' from an erect penis." 
doll play, description of the sexual act, and other evidence in the case clearly demonstrated that molestation had occurred.

Interpretation of doll play is complicated by parental coaching. Parents contending that abuse occurred may provide, even unwittingly, the sexual language and sexual knowledge that a child would not otherwise have (many parents, for example, expose their children to sexually oriented educational materials designed to show them how to avoid sexual abuse). Experts who conclude that children displaying ageinappropriate sexual knowledge must have experienced abuse may be making the unstated assumption that no coaching took place-an assumption that may well be untrue in the particular case.

While evidence from doll play alone is inconclusive, it can be of value if part of a total evidentiary picture that supports a finding of abuse. It is unhelpful if produced in ways that are too unreliable for legal factfinding purposes. To assess the evidence, a judge must learn in each case in which dolls are used: when and how the dolls were introduced into the investigation; what instructions or directions were given to the child about the doll; what the dolls looked like; and what had occurred in the investigation up to that point that might have influenced how the child responded to the dolls.

Courts must also distinguish two different uses of the dolls: (1) to interpret the child's play, and (2) to help the child make his or her own statements about the alleged abusive incident. In the first instance, the child's play does not directly communicate a memory of the event; rather, the play requires interpretation by the expert (e.g., the child violently throws the adult male doll across the room; the expert interprets this as anger against the accused). In the second type of doll use, the dolls inspire the child to make a statement about the abuse itself (e.g., the child recounts how and where the accused touched her, pointing to body parts on the doll). 
Each different use requires different legal assessment. How convincingly experts interpret play (for example, how they interpret body language, drawings, or other non-verbal behavior) depends upon the persuasiveness of the reasoning offered in support of their interpretation and upon how well this one interpretation fits into the entire evidentiary picture. How convincing the child's doll-facilitated statements are depends upon the credibility of the child in terms of recall, suggestibility, consistency with prior acts and statements, etc.

Perhaps the best resolution for now is that offered by one professional organization, the American Professional Society on the Abuse of Children:

Anatomically detailed dolls should be used with care and discretion. Preferred practice is to have them available for identification of body parts, clarification of previous statements, or demonstration by non- or low-verbal children after there is an indication of abuse activity.

The anatomically detailed dolls should not be considered a diagnostic test. Unusual behavior with dolls may suggest further lines of inquiry and should be noted in the evaluation report, but is not generally considered conclusive of a history of sexual abuse. ${ }^{67}$

\section{Evaluative techniques: the child interview}

Interviewing children is an art. The difficulties are considerable: some children may be unwilling to communicate at all; others may be too willing to say whatever they think the interviewer wants to hear. Researchers are just now beginning to explore children's capacity for understanding, for recalling details of past events, and for distinguishing truth from imagination. ${ }^{68}$ Courts now must deal with complex realities-for example, the fact that children's accounts may mix true stories of abuse with fantasy elements. ${ }^{69}$

Concerns about interviewing technique are especially acute in the area of child sexual abuse. As more courts are exposed to 
the techniques mental health professionals and law enforcement officials use to gather information from children, the pressure increases on these investigators to conduct their inquiries with greater care.

The Michaels case provides a catalog of interviewing pitfalls. The appellate court, reversing jury verdicts against Ms. Michaels on numerous sex abuse counts, recounted the ways in which investigators prejudiced the gathering of legally worthwhile information:

1. Many interviews contained extremely leading and/or suggestive questions.

2. Certain questions planted sexual information in the children's minds and supplied the children with knowledge and vocabulary which might be considered inappropriate for children of their age group.

3. Children were encouraged to help police "bust this case wide open."

4. Peer pressure and even threats of disclosing to the other children that the child being questioned was uncooperative were used. A child was told that she needed to talk to help her friends and that the investigator had already spoken to five other children who revealed what happened.

5. In some cases, certain children were told in detail what another child had disclosed.

6. Sexualized discourse was encouraged and applauded.

7. [A]ll of these young children were convinced, either by their own experiences, other children, investigators, parents, or some combination thereof, that defendant was "bad" because she had done "bad things" to children at Wee Care. . . . Children were told they could keep Kelly locked in jail by cooperating; therefore, they and their families would be safe.

8. In several instances, the children were tired and/or resistant to participating in the interviews, but the investigators continued to press for cooperation.

By using peer pressure and rewards, suggesting answers, supplying sexual knowledge and vocabulary, offering informa- 
tion from other child interviews, and forcing children to continue unwanted interviews, the investigators contaminated whatever results their interviews produced. This is not to say that there is no room for the occasional leading question, offer of sympathy, and reward for cooperation. The legal system should not set its evidentiary standards so high that children are deprived of compassion, care and sensitivity when they are asked to recall experiences of abuse. Nor should interviewers be held to an unattainable standard of perfection.

A child interview that produced persuasive evidence of abuse occurred in the child protective proceeding Matter of E.M. ${ }^{70}$ The court approvingly noted the interviewer's technique of asking some questions designed to test the child's capacity to recall and generally using "carefully phrased" interview questions. The judge was also impressed by the way in which the interviewer set forth her criteria for evaluating this nineyear-old child's account, specifically:

The child had a good capacity for accurate recall; the story was clear and coherent; the child related to the examiner in an ageappropriate manner; and significantly, the child's emotional reactions in the interview (what might be termed the child's "affect pattern") included manifestations of anxiety and shame that were consistent with post-traumatic stress, that is, the way individuals who have undergone traumatic events, in this instance sexual abuse, later recount the traumatic event."

Another interviewer in the case added that the child was "one of the most sexually preoccupied children he had seen in his long experience." Both experts' testimony fit in well with the other evidence in the case, including the consistency of the story the child told to several different people at different times, the child's own clear statement of the abusive act and identification of the abuser, and the child's attainment of the developmental capacity to render a reliable account of what had happened to her. 


\section{Biases: the influence of experts' own values, beliefs and attitudes}

Experts, like anyone else, are not value-free. In the words of one professor of psychology: "Subjectivity and perspective enter into their interpretations of research findings," and professional judgments are "shaped by their educational, social and political background." 72

Exactly how professional judgments are affected by personal background factors is difficult for an outsider to determine, even if all the relevant background facts were known. Psychiatrist Richard Gardner, writing of child custody evaluators, says that reminders of emotionally significant events in the expert's life create problems:

The therapist who has been involved personally in a custody battle, for his (her) own children, is not as likely to be as objective as the colleague who has not had the misfortune to be embroiled in such a conflict. The likelihood that such a therapist will identify irrationally or inappropriately with one of the parties is high. The likelihood that there will be similarities between the examiner's own experiences and that of one, or even both, of the clients is great. And such similarities are likely to evoke emotional responses that becloud objectivity. ${ }^{73}$

In the widely publicized Baby $M$. case, one expert testifying in the case had himself been involved in a bitter custody battle. ${ }^{74}$ This was Dr. Lee Salk, who testified in very strong terms against the baby's mother, Mary Beth Whitehead. ${ }^{\text {s }}$ Salk made his custody recommendation without ever meeting the mother; he claimed to be perfectly confident in forming his opinion based upon written reports filed by other experts in the case. This sort of dubious professional conduct suggests that experts be asked about their personal experiences, at least to see if there are direct parallels between the case at hand and the expert's own life experience.

Experts may also be influenced by personal reactions to people they meet in the litigation. Alan Levy has written of 
experts who are angered by lawyers or litigants they find irritating or obnoxious. Strong personal reactions, whether positive or negative, can be a powerful unconscious influence on the mental health examiner. ${ }^{76}$

Other sources of bias are commonplace personal beliefs and attitudes, such as a tendency toward optimism or pessimism:

The personal biases and prejudices of the psychiatrist which are evident in his daily activities are also difficult to exclude from his testimony. For example, one expert may be more optimistic than another. These biases are components of the human personality and must be accepted as such. ${ }^{n}$

Personal beliefs and professional beliefs blend together in the expert's own professional self-image. An expert may see herself in her profession as a pioneer, a child saver, an iconoclast, a reformer, a feminist, or an innovative theoretician, to name just a few possible roles. The chosen self-image may be entirely altruistic. Yet it may exert a subtle distortive influence on the expert's judgment in individual cases that are not good candidates for activism, innovation, theory building, etc.

Uncovering sources of bias is not an easy task. Hints of bias may appear in testimony that is emotionally delivered, resistant to change in light of new facts, or delivered with absolute certainty. An expert who distorts the known facts, places emphasis on seemingly irrelevant details, or is inappropriately harsh on one party or indulgent toward another may be acting out of personal beliefs and attitudes rather than professional expertise. ${ }^{78}$

\section{Advocacy by the "neutral" expert}

Although social scientists are "trained . . to disclose the weakness of their findings and the limitations of their methodology" and "to be modest about the implications of 
their studies and cautious about generalizing from their research findings to other situations, "'79 once they form a conclusion they may become advocates for their own opinion.

Lawyers and the legal atmosphere may pressure even the neutral expert to frame opinions in the most persuasive way possible and to do what's necessary to ensure that the expert's own conclusion prevails in court. In testifying, such an expert may lose the objectivity that he or she started out with at the beginning of the inquiry.

Dr. Bernard Diamond, attempting to expose the "fallacy of the impartial expert" many years ago, claimed that the reality of the courtroom environment and of human nature inevitably induced partisanship:

Because his testimony does in fact support one side of the legal battle . . . [the expert], if he is at all human, must necessarily identify himself with his own opinion, and subjectively desire that "his side" win. . . . [The expert may sometimes affect] a more aloof, detached facsimile of impartiality that masks his secret hope for victory of his own opinion. Such a detached witness may be totally unconscious of the innumerable subtle distortions and biases in his testimony that spring from this wish to triumph. ${ }^{80}$

Diamond's point, made in the context of insanity defenses in criminal law, can readily be extended to experts offering testimony in cases involving children. Once an opinion is formed favoring one party or another on the ultimate issue in the case, the expert's strong desire is to see his recommendations implemented, to ensure that justice is done for the child. Altruism strengthens partisanship, and objectivity suffers.

Advocacy of one's own opinion may lead to some commonly observed sins of omission and commission. Testimony may be shaped to draw attention to some facts and away from others. Reservations, difficulties or doubts are suppressed. Theories and conciusions are stated with confidence, however tenuous or weakly supported. ${ }^{81}$ There is no disclosure of uncertainty, imprecision, or ambiguity. 


\section{Commitment to one's own conclusion in the inquiry phase}

A problem related to advocacy on the witness stand occurs prior to the delivery of testimony, in the evaluation process. At some point in the course of the expert's inquiry, she will reach some conclusions, even if tentative, about key issues in the case. After that point, the expert's perceptions may be affected by those conclusions. It is a commonplace observation that one sees what one expects to see and screens out the rest. An evaluator who comes to the conclusion that a particular child is telling the truth about sexual abuse, for example, may thereafter pay careful attention to the accumulation of all positive evidence supporting that conclusion while dismissing contrary evidence as unlikely, unpersuasive, or inconsequential. $^{82}$

Experts who become wedded to their conclusions may resist significant evidence that contradicts them. The experience of the trial judge in Matter of Eli is instructive:

I heard expert testimony from Barbara Pilcher, a certified social worker, who was the child's psychotherapist. . . It was Ms. Pilcher who is responsible, in great part, for the mother's belief that the child was sexually abused by her father. One cannot escape the conclusion that subsequent events have caused her to become rigid in her opinion that sexual abuse occurred, even in the face of considerable evidence to the contrary.

An expert who suggests a mother's fears of abuse are true has to feel invested in and responsible for the vigorous litigation that is likely to ensue. Such an expert may feel as committed as any party to seeking vindication in court.

\section{Uncertainty and ambiguity in psychological knowledge}

No precision instruments exist to directly measure human nature or personality. Expertise in the areas of interest in 
family law is less advanced and less scientific than some mental health professionals might lead one to believe. ${ }^{83}$ Uncertainty and ambiguity bedevil the mental health profession (as they do the legal profession). Factions within the mental health community fight with each other, sometimes in fierce terms that don't surface when they testify in court. ${ }^{84}$ The facts of individual cases may not fit neatly into legal or mental health categories, and the categories themselves are sometimes suspect. As one psychologist has noted, human beings are so variable that the range of behavior considered "normal" overlaps the symptoms of mental disorder. ${ }^{85}$

In this context of scientific uncertainty, the basis for expert opinion must be carefully scrutinized. Opinions stemming from inferences about motives, relationships, and unconscious drives, and interpretations of verbal and non-verbal communication and overt behavior, must be adequately explained, not merely accepted as scientific truth.

Experts are often asked to help determine the sources of psychological symptoms. Why does a particular child, for example, display signs of emotional distress? One explanation offered by an expert in Matter of Eli was sexual abuse by the child's father. But alternative explanations were available as well. Other stressors having nothing to do with sexual abuse existed in the case. One was the fact that the father had suddenly moved out of the family residence without a word of explanation. His wife and daughter came home one day to find his possessions gone and pictures missing from the walls. This sudden collapse of family life was an obvious source of stress. Another was the marital breakdown itself, even without the dramatic exit of the father. In such cases, courts, and the lawyers they depend upon for evidence and argument, must consider and examine alternative explanations for children's behavior that are consistent with the known facts. 
Explanations of expert opinions are most essential when the expert ventures a prediction about the future. Predictions may be offered in custody cases, for example, about how one or both parents will behave with and care for the child in the future. If predicting future conduct is deemed essential to the legal system, experts may be unreasonably pressed to participate. Consider in this context how authors Bernard L. Diamond and David $W$. Louisell describe one response to a predict-the-future request:

Recently one of the authors received a letter from a judge who is chairman of a crime commission in his state. The letter requested information as to how a law might be formulated that would guarantee that no sexual offender would be discharged from an institution if he might commit a second offense after his release. The only logical answer to such an inquiry is the suggestion that the institution be placed in charge of a skilled and certified fortune-teller. Psychiatrists generally do not possess such abilities to predict the future. ${ }^{86}$

It is not entirely possible to avoid predictions about the future when the question is the welfare of a child in times to come. But experts need to stay close to their observations in the present when they make educated guesses about the future.

\section{Research and statistics}

Experts are regularly called upon to provide information from the research they or others have done in the field. While research knowledge is valuable, there are hazards in too readily accepting the reports of psychological research. Several of these hazards, for the three broad types of studies done in the field of psychology that experts draw upon in family law cases, are discussed below. ${ }^{87}$

The Researchers who study large populations attempt to derive epidemiological conclusions that are generally true for the group under method study. ${ }^{88}$ Their results offer general guidance to inquirers in 
particular cases (e.g., a study of suicidal people might identify factors to look for in deciding if a depressed parent in a custody case is suicidal).

It is important to note that these studies describe populations, not any individual person. By contrast, legal proceedings focus on specific children and adults, not on aggregations of people. Data and statistics that describe the characteristics of a group cannot be assumed to describe any individual member of that group..$^{89}$

Neither do population statistics prove cause-and-effect relationships. Characteristics of the population described by statistics may be related in a causative way, or the characteristics may be caused by an unknown factor in the population. Although experts may speculate about the causes of the population characteristics they discover, the numbers themselves do not answer causation questions.

The Research experiments can provide support for social science experimental testimony by experts. Experiments are more or less convincmethod ing depending upon the extent to which the experimental situation parallels real-world conditions, the methodology is sound, the findings are subject to peer review, and the results are replicated by others.

The psychologist's laboratory does not mirror the laboratory of researchers in the "hard" sciences. Diamond and Louisell observe that

psychological experimentation is strictly limited. One can rarely devise an experiment that would have the precision taken for granted by the chemist and the physicist. Scientific experimentation consists largely in rigorously controlling irrelevant factors and isolating the variable under investigation. Techniques for doing this are not easy to devise with human psychology. Important ethical and humane considerations block the performance of crucial experiments. 
Experts performing experimental research in psychology should be cautious about drawing general conclusions from a given experiment. A recent collection of research work on the child as witness by well-regarded researchers provides some useful examples. ${ }^{91}$ Researchers acknowledged such problems as the artificiality of their experimental situations (e.g., experimenters conveniently use college students as mock jurors, although real jurors are not typically college students and might respond very differently from college students). The fact that participants in psychosocial experiments know their actions will not have real-life consequences may lead them to behave in ways that differ from the ways they would behave in actual situations in life. Other drawbacks derive from particular experimental methods-e.g., the use of a single child actor in an experiment designed to test juror reactions to the "typical" 12 year-old child. In many instances, experimenters assume-without knowing - that their subjects will think and behave in the experimental situation in ways typical of larger populations that the subjects are presumed to represent.

The clinical One common research technique is to make an in-depth method examination of a small number of subjects. There are major problems with the use of such studies to derive general psychological principles. In small-scale studies, the few subjects cannot be assumed to be typical. How subjects were chosen may affect the results obtained. Studies supporting joint custody, for example, that look at a few families who volunteer to try this arrangement and who are willing to be studied doing it, can hardly justify broad conclusions about the viability of this type of custody arrangement for the general population of divorcing couples. ${ }^{92}$

Another problem with small-scale research is the frequent absence of control groups. One of the best-known studies of the effects of divorce on children is Wallerstein and Kelly's Surviving the Breakup. The authors studied only children of divorce, in 60 California families, without comparing them 
with a control group of children whose families remained intact. This makes it difficult to say that all the problems experienced by the children studied were due to their parents' divorces rather than to other troubling juvenile experiences.

Other research problems include questionable data-gathering techniques (e.g., determining if a custody arrangement is working out well for a child by asking the parents to fill out a questionnaire rather than by the direct observation of the family by the expert), the non-replication of findings, the drawing of conclusions that go beyond the limited data actually found, and the dependence upon assumptions drawn from the research of others. Finally, a body of research is rarely entirely consistent; experts should be asked if studies exist that cast doubt upon or contradict the particular results the expert has explained.

\section{Tests}

Much has been written about the misuse and overuse of testing. ${ }^{93}$ In family cases, legal professionals may ask for psychological tests to provide objective evidence. The literature, however, indicates that this is a false hope.

The general shortcomings of psychological testing of children for legal purposes include inappropriate use of traditional tests for purposes that differ from those for which the tests were designed; the uncertain effects of test administration on test results; the need for subjective interpretation of test responses; the lack of standardization of some test instruments; and the irrelevance of tests to the resolution of legal issues.

Dr. Richard Gardner states that in child custody evaluations, projective tests ${ }^{94}$ like the Rorschach (reactions to amorphous ink blots) or the Thematic Apperception Test (subject requested to make up a story about pictures shown to him) 
generally require too much speculation in their interpretation to be useful in assessing parental capacity or predicting parental behavior. He observes:

There are judges who will frequently, if not routinely, order psychological tests on both parents and/or children. As mentioned, this is a manifestation of the judge's naïveté. It reflects the court's view (promulgated by mental health professionals) that these tests are "objective" and that they provide information that is much more accurate than clinical observations. The judge here has probably been duped into the belief that there is something more objective and scientific about [such tests]. ${ }^{95}$

The result is testing that encourages "each party's bringing in a parade of professionals to provide different explanations for the same projective data."96

Another expert points out that assessment instruments like the Rorschach and Minnesota Multiphasic Personality Inventory (MMPI) tests "were not designed to assess parents' relationships to children, nor to assess parents' childrearing attitudes and capacities, and these are often the central questions in child custody cases." ${ }^{p 7}$

Marian Hall ${ }^{98}$ offers several reasons to discount the testing that is sometimes done in sexual abuse cases. She advises that the tests have "poorly standardized instructions" and that the use of "adolescent and adult projective techniques with preschool children to ascertain presence or absence of specific target events is invalid." She dismisses many "diagnostic devices that presume to give quick and absolute values to behavioral probabilities" as "equally questionable." She concludes:

If oversimplified and nonstandardized tests are no more appropriate than using traditional tests for nontraditional purposes, then it would appear that we are left with the task of using our best observational skills and, with the help of the normal accoutrements of play, allowing children to tell us in words and actions what they can about the events of their lives.99 
Experts trained in therapeutic practice and procedure may err if they unthinkingly transfer their professional standards of conduct to the litigation context. Some of the potential problems are described in the following four items.

\section{Factfinding by experts}

In their therapeutic work, clinicians do their own factfinding by taking histories, conducting interviews, and reviewing records. But in forensic evaluations, expert factfinding can be a hazard, sometimes destroying the value of the entire effort.

History-taking in the clinical practice of therapy may provide useful information about the patient's past. Success in treatment is not necessarily based upon accuracy in memory, however; the "historical truth" of what is said by the patient is of lesser moment than helping patients to function better in the present and to cope with their emotional problems, whatever the source. Even therapists who help a patient to progress toward improved mental well-being cannot vouch for the accuracy of memories of the past. ${ }^{100}$

Custody and other forensic evaluations are quite different contexts for history-taking. Interviewees are not seeking help, but trying to achieve a purpose. Parties to a custody battle will wish to persuade the expert of their superiority and their partner's inferiority. The motive to overstate, to embellish, and to distort the truth of past events, in order to win in litigation, is apparent.

An experienced evaluator, Dr. Alan Levy, identifies the expert's attempt to find the truth of past events as a major pitfall in child custody work. Levy describes how the custody evaluator is drawn into the morass of truth-seeking:

First you hear impassioned, lengthy and detailed allegations reading like a laundry list and then you are asked to read a stack of court papers. It is almost certain that you are going to be faced with dia- 
metrically opposed statements by the parents. At this point it is tempting to see if you can determine who is telling the "truth" and who is not. This can prove to be a fruitless and time-consuming mission and is best left to the courts.

Instead of trying to reconstruct past events, however relevant they may be, "[t] he evaluator is urged rather to rely on his/her clinical skills which emphasizes interviewing and observation of parents and children." 101

Writing about child sex abuse inquiries, Dr. Marian Hall indicates that evaluators can offer much of significance through observational analysis: "An experienced child psychologist, observing a child in its natural environment in the presence of the customary caretakers as well as in a one-to-one play situation, is able to assess developmental level, quality of attachment to parents or other caretakers, adequacy of stimulation and security in the environment, and to screen for the need for further specialized evaluations." 102

Experts who develop facts through firsthand observations are on much firmer ground than experts who try to do factfinding about past events in their offices. The latter may founder due to lack of access to all information sources or to reliance on accounts given by interested parties. Thus the expert may err if:

1. She accepts one party's version of the facts.

2. He accepts the facts told by any other self-serving or partisan informant (with the exception of admissions that run contrary to the party's own self-interest).

3. She relies on hearsay contained in records or supplied to her in conversations with parties or other informants.

4. He attempts to fill in gaps in the factual picture by making unwarranted factual inferences and assumptions.

Matter of $C / R$ Children ${ }^{103}$ presents an example of an erring expert accepting the facts told to him by a teenage girl alleging sexual abuse by her stepfather. The teenager related that 
before the alleged abuse she had been a "pretty good student," but that afterward she had difficulty even "getting up in the morning and going to school." The expert accepted the truth of this, and also accepted the young woman's description of her recent newly experienced sleep problems. But in court the facts of these matters emerged quite differently. School records showed that the girl was a no-show student with an extensive truancy record that extended back for months before the alleged abuse. And the supposedly new sleep problems were in truth not new at all, but longstanding symptoms of the girl's severe emotional problems.

The desire to fill in gaps in factual knowledge may lead experts to make questionable inferences and assumptions. ${ }^{104}$ This may account for some of the flaws in expert testimony that occurred in Allen v. Farrow. ${ }^{105} \mathrm{~A}$ team of experts from the Child Sexual Abuse Clinic at Yale-New Haven Hospital was asked to look into charges that filmmaker Woody Allen sexually abused his daughter Dylan. The team's report was deemed unreliable by the trial judge primarily because it:

1. Made visitation recommendations despite never having observed the parent and child interact together.

2. Drew conclusions about Satchel, another child in the custody dispute, though the team never saw him.

3. Concluded there had been no sexual abuse when the supporting data were inconclusive on the point. ${ }^{105}$

Clinicians hear many factual statements in the course of their inquiries, and it may not be practical to expect them to disregard all factual statements that are not proved according to some legal standard. It is important therefore, that experts be asked to disclose the source of the facts upon which they base their conclusions, with particular "efforts . . . made to distinguish those material facts and observations that the expert experienced firsthand from those known to the expert via secondary sources." 107 
Determining where the truth lies may require a broader investigation than the expert is able to undertake. In court, the judge may hear from a wider set of characters than the expert. ${ }^{108}$ The expert lacks certain factfinding tools available in the courtroom. To facilitate factfinding, the legal system provides such devices as subpoena power, compelled testimony under oath, and cross-examination. When conflicting stories are told by fierce partisans engaged in a battle over a child, these tools may be essential to any hope of uncovering the truth.

\section{Use and assessment of evidence}

In their own practices, mental health experts may make recommendations or take actions based upon evidence that would not be sufficient for the legal system, given the legal system's different purposes and standards of proof. The therapeutic enterprise is a practical effort to improve mental health. If some treatment course might work, based upon some evidence, perhaps incomplete or uncertain, a clinician may initiate it. Decisions may be difficult precisely because evidence is scant, but "clinicians . . . are trained to tolerate ambiguity while providing concrete recommendations, often with an exaggerated voice of authority (which it is thought may have its own therapeutic effects)."109

Judge Bazelon characterized the "clinical mind-set" as one that

no matter how informed by scientific education, is practical. It seeks to find ways to help clients now. It knows that practice precedes knowledge and that to await certain knowledge is to abdicate practice. Sometimes this practical sense translates into . . . overconfidence. . . .10

Acting in accordance with their training, experience and practical mind-set, mental health professionals may testify to "findings" and conclusions that are not supported enough to 
satisfy a legal judgment with enduring legal consequences (even though the evidence might satisfy the professional's "reasonable basis for treatment" standard). ${ }^{111}$

\section{Anecdotal evidence from the limited universe of clinical practice}

Another potential contaminant of clinical judgment is the inevitable influence of the particular set of clinical experiences of the expert. This is essentially the problem of drawing conclusions from studies using small sample sizes; the sample here is the clinician's own practice. While we expect clinicians to learn from experience, there is no guarantee that these experiences are typical, and general propositions drawn from them may be erroneous.

Despite limited information provided by clinical practice, one commentator claims that "clinicians frequently are sufficiently enamored of the value of clinical observations that they regard verification of outside factual information tending to confirm their clinical conclusions as unnecessary and a waste of time."

\section{Distorting effects of therapeutic qualities such as empathy and loyalty}

In a therapist, empathy is good; in an evaluator, it may be an impediment to accuracy and objectivity. When a mental health expert who has been treating one of the parties testifies, he may feel loyalty to and empathize with his patient. A therapeutic alliance can be helpful in the effort to relieve psychic suffering, but it can be a source of bias and error in forming objective opinions for legal purposes. ${ }^{113}$

Even where there is no prior therapeutic relationship, the expert's empathetic responses may be aroused by one of the 
parties. Neutral evaluators may be tempted to engage in some therapeutic work with the evaluation subject. Psychiatrist Alan A. Stone writes that "once the forensic examiner has decided that his or her testimony will be helpful to the evaluee, it is not unusual to permit the relationship to become an intensely therapeutic encounter. Thus the expert often enters the deposition or courtroom deeply involved in a transference/countertransference. . . ."14 Objectivity is sacrificed when the expert/therapist gets emotionally involved with and professionally committed to the evaluee/patient. ${ }^{115}$

\section{Special concerns of mental health professionals about the risk of error}

A psychology expert in a child abuse case may be affected by her judgment about which is worse: to err in saying abuse occurred when it didn't, or to err in concluding it did not occur when it did. While experts may profess equal concern about making either error, it is at least plausible that those with an intimate personal or professional knowledge of the horrors of child abuse would be inclined to more strenuously avoid the possibility of sending a child back into the arms of an abuser. To borrow from legal terminology, such an expert might consider evidence that abuse occurred as overcome only by clear and convincing evidence-or even evidence beyond a reasonable doubt-that it did not. ${ }^{116}$

\section{Conclusion}

After surveying the difficulties in assessing the quality of expert testimony in children's cases, I suggest a few conclusions for professionals involved in these cases to consider.

1. Don't pressure experts for "the answer." All too frequently they don't know it, although some are too willing to offer an opinion that goes beyond their role and the evidence 
they have to offer. It is best to define their role as developers of information through interviewing and observation, as theorists explaining the significance of facts, and as articulators of matters not within the everyday experience of laypersons.

2. Integrate experts' evidence with the traditional sources of evidence gathered by courts. Mental health professionals are just part of the total effort to answer questions relevant to the law. Every source of information contributes to the overall picture that must be the basis for a judicial decision.

3. Evidence that doesn't require expertise ought not to be slighted. For example, the parties in a custody case may offer uncontradicted accounts detailing the amount of time each has spent with their child and the actual caretaking each has performed. This deserves considerable weight in the outcome, whether experts testify or not.

4. Don't write off partisan experts-they may be a needed corrective to a poor-quality neutral expert. Psychologists Aber and Repucci observe that "there is often no substitute for another point of view from a qualified critic."117 Allen $v$. Farrow demonstrates the use of a qualified critic to elucidate the inadequacies of a report by a team of "neutral experts."

5. Recognize that the available knowledge from psychology is in flux, at times full of ambiguity, at times frustratingly inconclusive. The mental health profession is now in a process of discussing, suggesting, proposing theories, inventing protocols, and refining or replacing earlier ideas about issues relevant to children's issues in court. The profession has its internal disagreements and its competing theorists of every stripe and description. Its practitioners include pioneers, rescuers, self-promoters, activists with special agendas, traditionalists, idealists, innovators, reformers, eccentrics and oddballs; in short, the same cast of characters as in any other profession. 
The best expert offers not just educated opinions, but facts developed in the course of the professional evaluation, coherent explanations, and wisdom. Back in 1976 New York State Chief Judge Charles Breitel wrote what are fitting final words about experts in cases involving children:

In custody matters parties and courts may be very dependent on the auxiliary services of psychiatrists, psychologists, and trained social workers. This is good. But it may be an evil when the dependence is too obsequious or routine or the experts too casual. Particularly important is this caution where . . . publicly compensated experts or experts compensated by only one side have uncurbed leave to express opinions which may be subjective or are not narrowly controlled by the underlying facts. ${ }^{118}$

Notes 1. Jerome Frank, Courts on Trial, ch. 3 (1949).

2. See Renee B. v. Michael B., _ A.D.2d $\rightarrow 611$ N.Y.S.2d 831 (Ist Dept. 1994) and Rentschler v. Rentschler, _ A.D.2d $\longrightarrow 611$ N.Y.S.2d 523 (1st Dept. 1994) for two cases in which trial courts' custody awards were reversed because the appellate court deemed independent experts' testimony more persuasive than the trial judges did. One trial judge subsequently held that a lawyer would be permitted to be present at his client's court-ordered forensic examination in a custody case, because the expert's interview might be more important than anything that happened in the courtroom. Koons v. Koons, N.Y.L.J. 6-20-94 (Saxe, J.).

3. David Bazelon, A jurist's view of psychiatry, 3 J. Psychology and L. 175 (1975) (emphasis added).

If even the experts are only guessing, then perhaps the best metaphor for modern trials is not Judge Frank's civilized "fight" but rather a 1950 s quiz show, where the litigants pose the $\$ 64,000$ question (e.g., Was this child sexually abused by her father?), the witnesses offer their best answers, and everyone waits in suspense until the host (the trial judge) declares the winner. But instead of a correct answer waiting patiently in a sealed envelope, there is only a puzzled judge, valiantly trying to weigh the quality of the answers offered by the contestants in court.

4. This is acknowledged in Nelson v. Farrey, 874 F.2d 1222, 1228 (7th Cir. 1989) (regarding investigation of child sex abuse allegations).

5. Jeffry $H$. Gallet, Judicial management of child sexual abuse cases, 23 Fam. L.Q. 477, 483 (Fall 1989). 
6. Diamond and Louisell, The psychiatrist as expert witness: Some ruminations and speculations, 63 Mich. L. Rev. 1335, 1341 (1965).

7. See Matter of Eli, 607 N.Y.S.2d 535 (Fam. Ct., NY Cy, 1993) (Gallet, J.) for a useful discussion of the variety of credentials that different experts possess.

8. Marian D. Hall, The role of psychologists as experts in cases involving allegations of child sexual abuse, 23 Fam. L.Q. 451 (Fall 1989).

9. Jeffry Gallet, Judicial management of child sexual abuse cases, 23 Fam. L.Q. 477, 482 (1989).

10. Professor Randolph N. Jonakait points out that "Experts do not always learn when their opinions are wrong. The psychiatrist making predictions about dangerousness, for example, will not necessarily discover that a characterization was incorrect. The wrong assessment of dangerousness that causes restraint will probably not be apparent. ... The psychiatrist's experience will not teach her about the faulty nature of her premises. Her experience will not validate her opinion on dangerousness." Randolph N. Jonakait, Real science and forensic science, 1 Shepard's Expert \& Scientific Evid. Q. 435, 453 (1994). See also David Faust and Jay Ziskin, The expert witness in psychology and psychiatry, 241 Science 31 (July 1, 1988) at 33 ("Clinicians often receive little or no outcomes information or feedback about their judgments, which precludes self-correction.").

11. 537 A.2d 1227 (N.J. 1988).

12. Russell Baker, "Mom Flunks Patty-Cake," N.Y. Times, Feb. 28, 1987 at 31 .

13. See, e.g., Matter of C/R Children, N.Y.L.J. May 24, 1993 (Fam. Ct.) (expert talks on phone with social worker who he mistakenly believes is the child's therapist; also fails to consult persons familiar with or records revealing child's longstanding mental problems).

14. Dianne Skafte, Child Custody Evaluations: A Practical Guide (1985) at 25. Dr. Richard Gardner suggests a range of 20 to 40 hours for his average custody evaluation. See Gardner, FamiLY Evaluation in Child Custody Mediation, Arbitration and Litigation (1989) at 79. Benedek and Schetky state that the "child custody assessment is a complicated and time-consuming evaluation" but do not suggest a minimum amount of time for an adequate assessment. Benedek and Schetky, Custody and visitation problems and perspectives, 8 Psychiatric Clinics of N. Amer. 587 (1985). 
15. Evaluating allegations of child sexual abuse: The "validation" process, in Sexual Abuse of Children 213 (published by the Appellate Division of the Supreme Court of the State of New York, First Department 1991).

16. Alan M. Levy, Major pitfalls in child custody evaluation, Psychiatry Letter (Fair Oaks Hospital, April 1984).

17. Id. One text also calls attention to the "acute and disorganizing stress" occurring at the time of divorce, complicating evaluation because of the atypical level of functioning displayed by the parents. Melton, Petrilla, Poythress, and Slobogin, Psychological EVALUATION For the COURTS: A HANDBOOK FOR MENTAL HeAlTH PROFESSIONALS $§ 13.01$, at 329-330 n.10.

Others have noted the variability of people and the risk of drawing misleading conclusions in different psychiatric contexts. See B. Ennis and T. Litwack, Psychiatry and the presumption of expertise: Flipping coins in the courtroom, 62 Calif. L. Rev. 693, 722-24 (1974) ("Since even 'normal' people speak and behave differently from one day to the next, it is no less natural for an allegedly mentally ill individual to appear agitated one day and composed the next. Consequently, the timing of a prospective patient's examination may substantially influence the diagnosis he or she is given."). Faust and Ziskin note that experts who review a single interview-a snapshot of the subject-often disagree on diagnosis and on conclusions to be drawn from the interview. David Faust and Jay Ziskin, The expert witness in psychology and psychiatry, 241 Science 31 (July 1, 1988).

18. A text in family law contains a custody trial transcript in which an expert asks a mother to put her child into an uncomfortable chair that the child does not want to sit in. When she does so in a way the expert considers inappropriate, he regards this as evidence of her general inability to handle stress. But the mother in a custody interview may feel such intense stress in responding to the evaluator's difficult directive that attributing her inadequate performance to personality or parental deficits, rather than to simple nervousness, seems unjustified. Judith Areen, CASES AND MATERIALS ON FaMILY LAW 514 (3d ed. 1992).

19. For extensive discussions concerning the conduct of the child custody evaluation, see Dianne Skafte, Child Custody Evaluations: A Practical Guide (1985) and Richard Gardner, Family Evaluation in Child Custody Mediation, Arbitration AND LITIGATION (1989).

20. Judge Gallet feels that the child's schoolteacher is an important, and often overlooked, source of behavioral information in sexual abuse cases. Presumably the teacher can provide information about the 
child's behavior and functioning both before and after an alleged incident of sexual abuse. Jeffry $\mathrm{H}$. Gallet, Judicial management of child sexual abuse cases, 23 Fam. L.Q. 477 (Fail 1989).

21. See Dianne Skafte, Child Custody Evaluations: A Practical Guide at 122; Richard Gardnet, Family Evaluation IN ChILD Custody MEDIATION, ARBITRATION AND LITIGATION at 325.

22. Matter of Eli, 607 N.Y.S.2d 535 (Fam. Ct., NY Cy, 1993) (Gallet, J.).

23. N.Y.L.J., May 24, 1993 (Fam. Ct.).

24. Commonwealth v. Gallagher, 547 A.2d 355 (Pa. 1988).

25. The final decision is this extended litigation in two states was handed down by the Michigan Supreme Court. DeBoer v. Schmidt, 443 Mich. 1204, 505 N.W.2d 575 (1993). The case was avidly followed by the public. See, e.g., Newsweek cover story, "Who's Looking After the Interests of Children?" (Aug. 16, 1993).

26. Testimony of Dr. Jack Novick, Schmidt v. DeBoer, No. 92-44098DR, Circuit Court, Washtenaw Cy, Mich. (1993).

27. Diamond and Louisell observe that "to make deductions about the mind . . . the observer must have a theoretical framework in which to order, explain and interpret his observations. . . . Further, his inferences, as well as his observations, are strongly colored by the qualities of his observing instrument: that is, his own personality, experience, and theoretical training." Diamond and Louisell, The psychiatrist as expert witness: Some ruminations and speculations, 63 Mich. L. Rev. 1335, 1341 (1965).

28. See David Bazelon, Veils, values, and social responsibility, 37 Amer. Psychologist 115 (1982) (elaborating the "sins of nondisclosure," including experts' failure to disclose methods and reasoning, theoretical perspectives, uncertainties and differences of professional opinion, and underlying value choices).

29. Richard Gardner. Family Evaluation in Child Custody MEdiation, ARBIrRation aNd Limigation (1989) at 205-206.

30. The categorization of homosexuality as a mental disorder disappeared from the American Psychiatric Association's Diagnostic and Statistical Manual, but different theoretical conclusions about sexual orientation may be held by individual psychiatrists. For one explanation of this, see Stone, Presidential address: Conceptual ambiguity and morality in modern psychiatry, $137 \mathrm{Am}$. J. Psychiatry $887,890-891$ (1980). Note also that although the word "homosexuality" disappeared, the concept is still to be found under 
$\S 302.90$, Sexual Disorder Not Otherwise Specified (persistent and marked distress about one's sexual orientation).

31. Richard Gardner, Family Evaluation in Child Custody MEdiation, ARBITRATION AND LITIGATION, 221-222.

32. E.g., N.Y. Dom. Rel. L. § 70(a) (McKinney 1994 Supp.) (disallowing gender considerations). But see Green v. Green, N.Y.L.J., July 14,1988 , at 23 , col. 5 (Sup. Ct.), criticized in Stephen A. Newman, A tale of two cases: Reflections on psychological and institutional influences on child custody decisions, 34 N.Y.L.S. L. Rev. 661, 662-671 (1989). Cf. In re Baby M., 109 N.J. 396, 537 A.2d 1227 (1988) (expressing preference for mothers of infants while case is pending); Richard Gardner, FAMILY EVALUATION IN Child Custody Mediation, ARbitration and Litigation 215-225 (special tie in fact exists during first two years between mother and infant because of physical experience of pregnancy, delivery, and breastfeeding).

33. "The 'psychological parent' argument has been criticized by a number of mental health authorities. The Group for the Advancement of Psychiatry, for instance, has contended that it is an oversimplification to think that all children have only one psychological parent. Additionally, it appears that Goldstein, Freud and Solnit ignored the wealth of literature bearing on the issues while relying heavily on clinical intuitive assumptions." Lyman and Roberts, Mental health testimony in child custody litigation, 9 L. \& Psychology Rev. 15, 22 (1985).

34. See Wallerstein and Kelly, Surviving The BrEakup: How Parents AND CHILdREN COPE WITH DIVORCE (1982).

35. Richard Gardner, Family Evaluation in Child Custody MEDIATION, ARBITRATION AND LITIGATION, 221.

36. Black \& Cantor, Child Custody, 181.

The basic problem of priority setting may characterize all of psychology. Dr. Alan Stone poses the dilemma of modern psychiatry this way:

How does the individual eclectic psychiatrist who conscientiously considers all of these factors [the biological, the psychodynamic, the behavioral, and the social psychological] reach a judgment about their relative significance?

This is our greatest weakness. We do not know what weight to give each perspective's account. . . . We can in rare instances assert with confidence the primacy of a particular account. But most often we are condemned to the ultimate ambiguity that is the inevitable consequence of our eclecticism. This is not a problem to 
be resolved by mere numbers; we do not have a formula or a way of deciding how much something should count.

Stone, Presidential address: Conceptual ambiguity and morality in modern psychiatry, 137 Am. J. Psychiatry 887, 889 (1980).

37. Loftus and Rosenwald, Buried memories, shattered lives, ABA Journal, November 1993, at 70.

38. Walter Reich, The monster in the mists, N.Y. Times, May 15, 1994, sec. 7, p. 1 (book review).

39. Id. See also Jane Gross, "Memory therapy" on trial: Healing or hokum? N.Y. Times, April 8, 1994, at Al.

40. State v. Michaels, 625 A.2d 489, 264 N.J. Super. 579 (N.J. Super. A.D., 1993), aff'd 136 N.J. 299 (1994) (affirming requirement of pretrial hearing on evidence tainted by improper child interviewing techniques).

41. This syndrome is called by various names-e.g., child sexual abuse syndrome, intrafamilial child sex abuse syndrome, child abuse accommodation syndrome. Mary Ann Mason, A judicial dilemma: Expert witness testimony in child sex abuse cases, J. Psychiatry \& L. 185,189 (Fall-Winter 1991). Experts may also refer to posttraumatic stress disorder (PTSD), a recognized mental diagnosis that does not imply that the disorder is caused by any specific cause such as sex abuse. See Alan A. Stone, Post-traumatic stress disorder and the law: Critical review of the new frontier, 21 Bull. Am. Aca. Psychiatry Law 23 (1993).

42. State v. Margaret Kelly Michaels, 625 A.2d 489, 264 N.J. Super. 579 (N.J. Super. A.D., 1993), aff'd 136 N.J. 299 (1994) (affirming requirement of pretrial hearing on evidence tainted by improper child interviewing techniques).

43. See State v. Bowker, 249 Cal. Rptr. 886 (Cal. App. 1988) at 890 n.8 for another criminal case that refused to allow experts to testify in this manner, or even to refer to the syndrome when using it for admissible purposes. Discussing the child sexual abuse accommodation syndrome (CSAAS), the court said:

Detailed testimony describing the syndrome itself is neither relevant nor necessary to rebut the sorts of misconceptions [jurors may have about child abuse]. The syndrome assumes the child is a "legitimate victim" of sexual abuse; its purpose is to explain why such victims exhibit certain types of behavior so as to assist psychology professionals in providing therapy and treatment. An expert has little need to refer to the syndrome in order to testify that a particular type of behavior is not inconsistent with a child having been abused. 
44. Robert Levy, Using "scientific" testimony to prove child sexual abuse, 23 Fam. L.Q. 383, 393 (Fall 1989).

45. Roland Summit, Abuse of the child sexual abuse accommodation syndrome, l J. Child Sexual Abuse 153 (1992).

46. Id. at 153 .

47. Id. at 156.

48. Id. at 158,160 (emphasis in original).

49. See, e.g., Matter of Linda S., 560 N.Y.S.2d 181 (Fam. Ct. 1990).

50. Compare Matter of Nicole V., 71 N.Y.2d 112, 524 N.Y.S.2d 19 (1987) (holding syndrome admissible in child protective proceeding) with State v. Duell, 163 A.D.2d 866, 558 N.Y.S.2d 395 (4th Dept. 1990) (holding child sexual abuse accommodation syndrome inadmissible to prove that child was sexually abused in criminal case).

51. See Roland Summit, Abuse of the child sexual abuse accommodation syndrome, 1 J. Child Sexual Abuse 153 (1992); Marian D. Hall, The role of psychologists as experts in cases involving allegations of child sexual abuse, 23 Fam. L.Q. 451 (Fall 1989) at 453 ("expert should not be asked . . . whether or not the abuse actually occurred as alleged").

52. Summit, supra note 45 at 160 .

53. Marian D. Hall, The role of psychologists as experts in cases involving allegations of child sexual abuse, 23 Fam. L.Q. 451, 463464 (Fall 1989).

54. Id. at $463-464$.

55. See S. Ceci, D. Ross \& M. Toglia (eds.), Perspectives on ChildRen's Testimony (New York: Springer-Verlag, 1989); same eds., CHILDREN's Eyewitness MEMORY (1987). For a summary of some research results, see Mary Ann Mason, A judicial dilemma: Expert witness testimony in child sex abuse cases, J. Psychiatry \& L. (Fall-Winter 1991) at 185, 206-211.

56. Doe v. U.S., 976 F.2d 1071 (7th Cir. 1992) (affirming the trial court's finding of abuse).

57. Even if sex abuse cannot be proved, though some evidence points to it, the court may have enough related information to take custody away from the suspected abuser. In Allen v. Farrow, the father's abuse of the child was not proved, but evidence was sufficient for the trial judge to conclude that Mr. Allen's other behavior with that 
child was inappropriate in a parent-child relationship. The judge permitted only supervised visits. Allen v. Farrow, N.Y.L.J. June 8, 1993 (Sup. Ct., Wilk, J.), aff'd - A.D.2d - 611 N.Y.S.2d 859 (1st Dept. 1994). See also a suggestion from Prof. Myers that a "child's out-of-court statements expressing fear or dislike of the parent accused of sexual abuse can constitute sufficient evidence to support a custody or visitation order. . . . if the child believes he or she has been molested by the accused parent, placing limits on interaction with the parent may be in the child's best interest." John E.B. Myers, Allegations of child sexual abuse in custody and visitation litigation: Recommendations for improved fact finding and child protection, 28 J. Fam. L. 1, 36 (1989-90).

58. Nelson v. Farrey, 874 F.2d 1222, 1225 (7th Cir. 1989).

59. Marian D. Hall, The role of psychologists as experts in cases involving allegations of child sexual abuse, 23 Fam. L.Q. 451, 461 (Fall 1989). Hall goes on to contrast the revealing nature of unstructured play with such materials with the use of anatomically correct dolls, but she does not discuss the dolls and merely notes that criticism of them has been made. Id. at 461 n.24.

60. See In re Amber B., 236 Cal. Rptr. 623 (Cal. Ct. App. 1987).

61. Robert Levy, Using "scientific" testimony to prove child sexual abuse, 23 Fam. L.Q. 383 (Fall 1989).

62. State v. Margaret Kelly Michaels, 625 A.2d 489, 264 N.J. Super. 579 (N.J. Super. A.D., 1993).

63. Matter of Rinesmith, 376 N.W.2d 139 (Mich. App. 1985). See also Cleaveland v. State, 490 N.E.2d 1140 (Ind. Ct. App. 1986); Vera v. State, 709 S.W.2d 681, 686 (Tex. Ct. App. 1986) ("use of dolls is often critical when the complainant witness is very young").

64. See, e.g., Perry and Wrightsman, THE ChILD WITNess 148-151, 188189 (1991). After reviewing the debate, these authors conclude that "to routinely exclude dolls play as tainted goes too far." Id. at 189. For a case in which a child mixed fantasy with reality and the court found sexual abuse, see Doe v. U.S., 976 F.2d 1071 (7th Cir. 1992).

65. Nelson v. Farrey, 874 F.2d 1222, 1228 (7th Cir. 1989).

66. Id. at 1229.

67. A.P.S.A.C. statement quoted in Ann H. Meltzer and April Kuchuk, Evaluating allegations of child sexual abuse: The "validation" process, in Sexual Abuse of Children 213, 220 (published by the Appellate Division of the Supreme Court of the State of New York, First Department 1991). 
68. See citations, infra note 91 .

69. In Doe v. U.S., 976 F.2d 1071, 1078, 1081 (7th Cir. 1992), one child said a dog drove her in a police car to a safe place, and another spoke of cages and fires. Both were found to have been abused, despite the fantasy elements in their accounts.

70. 137 Misc.2d 197, 520 N.Y.S.2d 327 (Fam. Ct. 1987).

71. Id. at 200.

72. Sharon D. Herzberger, Social science contributions to the law: Understanding and predicting behavior, 25 Conn. L. Rev. 1067 (1993). Accord, Aber and Repucci, The limits of mental health expertise in juvenile and family law, 10 Int'l J. L. \& Psychiatry 167 (1987).

Even the "hard" sciences take account of bias. Experimental medical research utilizes the "double blind" methodology, in which neither researcher nor subject knows, for example, whether the pill being administered is a placebo or not, to eliminate the chance of participant bias. See Nicholas Wade, Method and madness, N.Y. Times Magazine, May 22, 1994, at 20.

73. Richard Gardnet, Family Evaluation in Child Custody MEdiation, ARBITRATION AND LITIGATION 47 (1989).

74. The expert's custody victory over his own wife is reported in Salk v. Salk, 89 Misc.2d 883, 393 N.Y.S.2d 841 (Sup. Ct. 1975), aff'd 53 A.D.2d 558, 385 N.Y.S.2d 1015 (Ist Dept. 1976).

75. See Hornblower, "Baby M's mother called unstable by psychologist; but witness says he never met her," Washington Post, Feb. 11, 1987, at $\mathrm{A} 3$.

76. Alan M. Levy, Major pitfalls in child custody evaluation, Psychiatry Letter (Fair Oaks Hospital, April 1984).

77. Leigh M. Roberts, Some observations on the problems of the forensic psychiatrist, 1965 Wisc. L. Rev. 240, 257.

78. Two experts, putting the matter into psychological terms, write: "The expert ... like everyone else has certain personal opinions. It is the intensity of these opinions that signals a countertransference problem." Schetky and Colback, Countertransference on the witness stand: A flight from self? 10 Bull. Amer. Aca. Psychiatry \& L. (1982) at 118.

79. Sharon D. Herzberger, Social science contributions to the law: Understanding and predicting behavior, 25 Conn. L. Rev. 1067 (1993). 
80. Bernard Diamond, "The fallacy of the impartial expert," 3 Arch. Crim. Psychodynamics 221, 222-223 (1959). In the context of criminal cases, he adds that

... psychiatrists who do a good deal of defense work are apt to be unconsciously identified with the defendant, to be overly sympathetic, and motivated to be an advocate for the underdog. ... those psychiatrists who seek out appointment by the court as a so-called impartial witness have an equal probability of being overly identified with authority, of being a sort of watch-dog of the public morals, and motivated towards seeing that no criminal "gets away with anything."

81. Stone describes how it is "commonplace for highly principled nonforensic psychiatrists to lose their clinical balance in the courtroom and become partisan advocates of highly tenuous clinical or scientific opinions." Alan A. Stone, Revisiting the parable: Truth without consequences, 17 Int'l J. L. \& Psychiatry 79 (1994) at 88.

82. Judge Gallet writes of the unskilled evaluator who, in a sexual abuse case, will "concentrate on the indicators that the child is telling the truth and fail to note the absence of signs of trauma." Jeffry $\mathrm{H}$. Gallet, Judicial management of child sexual abuse cases, 23 Fam. L.Q. 477, 483 (Fall 1989). Faust and Ziskin complain of experts who devote "selective attention to supportive evidence" and who "overvalue supportive evidence and undervalue counterevidence." The expert witness in psychology and psychiatry, 241 Science 31 (July 1,1988 ) at 33,34 .

83. See Aber and Repucci, The limits of mental health expertise in juvenile and family law, 10 Int'l J. L. \& Psychiatry 167 (1987) at 170 ("the limits of mental health expertise have become painfully obvious in recent decades"; the authors also note the "limited ability of legal and mental health professionals to define and pursue the best interests of youth").

84. Researchers sharply critical of child sexual abuse experts, for example, have argued that such experts are unreliable in cases of alleged sexual abuse. Horner, Guyer, and Kalter, The biases of child sexual abuse experts: Believing is seeing, 21 Bull. Am. Acad. Psychiatry \& L. 281 (1993). Marian Hall notes that the "gap between the activist child rescuers and the developmental research teams seems unbridgeable." Marian D. Hall, The role of psychologists as experts in cases involving allegations of child sexual abuse, 23 Fam. L.Q. 451 (Fall 1989) at 456. Others have cast doubt upon the whole enterprise of forensic psychiatry. See Ziskin, CoPING WITH PSYCHIATRIC AND PSYCHOLOGICAL TESTIMONY (3rd ed. 1981).

85. David Faust and Jay Ziskin, The expert witness in psychology and psychiatry, 241 Science 31 (July 1, 1988) at 33 (or, to put it another 
way, all of us are a little bit nuts). Cf. Richard Gardner. FAMILY Evaluation in Child Custody Mediation, ARbitration and LITIGATION 284 ("The dream of the healthiest person utilizes the logic of the psychotic.").

86. Diamond and Louisell, The psychiatrist as expert witness: Some ruminations and speculations, 63 Mich. L. Rev. 1335, 1343 (1965).

87. See Matter of Eli, 607 N.Y.S.2d 535 (Fam. Ct., NY Cy, 1993) (Gallet, J.) for a valuable judicial discussion of these sources of knowledge, and Elizabeth Loftus and John Monahan, Trial by data, 35 Am. Psychologist 270 (1980) for an explanation of terminologye.g., internal validity, external validity, and consensual validity.

88. See Sharon D. Herzberger, Social science contributions to the law: Understanding and predicting behavior, 25 Conn. L. Rev. 1067 (1993).

89. "Empirical research in the behavioral sciences most often attempts to learn about how individuals behave by studying groups of individuals and extracting from them the average or typical behavior. Of course, no such 'average' person exists." Aber and Repucci, The limits of mental health expertise in juvenile and family law, 10 Int'l J. L. \& Psychiatry 167, 178 (1987).

90. The psychiatrist as expert witness: Some ruminations and speculations, 63 Mich. L. Rev. 1335, 1341 (1965).

91. S. Ceci, D. Ross \& M. Toglia (eds.), Perspectives on Children's TESTIMONY 19, 25, 33, 68, 74, 93, 189 (New York: Springer-Verlag, 1989).

92. Early, very positive joint custody studies were like this, with smallscale studies-one study examined as few as four families-used to justify major conclusions about the general effectiveness of this custody arrangement. See discussion of studies in Susan Steinman, Joint custody: What we know, what we have yet to learn, and the judicial and legislative implications, 16 U.C. Davis L. Rev. 739, 740-743, 758-760 (1983).

93. See, e.g., Stephen J. Gould, The Mismeasure of MAN (New York: W.W. Norton, 1981).

94. "Projective tests are so named because the person tends to project his psychological make-up and proclivities without conscious awareness." They generally provide an amorphous stimulus to which the subject is asked to respond. "The rationale of projective tests is that an individual's basic needs, drives, personality structure, etc., are not readily revealed by observing his overt behavior. . . ." 
Elliot R. Levine, Psychologist as expert witness in "psychiatric" questions, 20 Cleve. St. L. Rev. 379, 381-382 (1971).

95. Richard Gardner, Family Evaluation IN Child Custody MEDIATION, ARBITRATION AND LITIGATION at 285, 293-294.

96. Id.

97. Gary Melton, Psychological Evaluation for the Courts: A HandBook for Mental Health Professionals § 13.01, at 329-330, n.10.

98. Marian D. Hall, The role of psychologists as experts in cases involving allegations of child sexual abuse, 23 Fam. L.Q. 451, 460461 (Fall 1989).

99. Id.

100. See Wesson, Historical truth, narrative truth, and expert testimony, 60 Wash. L. Rev. 331 (1985); Tyson v. Tyson, 727 P.2d 226, 229 (Wash. 1986): "While psychoanalysis is certainly of great assistance in treating an individual's emotional problems, the trier of fact in legal proceedings cannot assume that it will produce an accurate account of events in the individual's past." But for an example of a court allowing a psychiatrist to rely upon a history provided by subject, see State v. Allewalt, 517 A.2d 741 (Md. 1986) (rape case).

101. Alan M. Levy, Major pitfalls in child custody evaluation, Psychiatry Letter (Fair Oaks Hospital, April 1984).

102. Marian D. Hall, The role of psychologists as experts in cases involving allegations of child sexual abuse, 23 Fam. L.Q. 451, 460 (Fall 1989).

103. Supra note 22 .

104. For a description of this phenomenon, known as "filling," on judging in custody cases, see Stephen A. Newman, A tale of two cases: Reflections on psychological and institutional influences on child custody decisions," 34 N.Y.L.S. L. Rev. 661 (1989).

105. Allen v. Farrow, N.Y.L.J. June 8, 1993 (Sup. Ct., Wilk, J.), aff'd A.D.2d -, 611 N.Y.S.2d 859 (1st Dept. 1994).

106. Id.

107. Aber and Repucci, The limits of mental health expertise in juvenile and family law, 10 Int'1 J. L. \& Psychiatry 167 (1987) at 181. The writers also call for disclosures of "[t]he rationale or justification for collecting or reporting the particular facts or observations, including the quality and type of research upon which they are based . . . the 
clinical or scientific principles or theories used to interpret the data or to make inferences from it" as well as the limitations and uncertainies of the expert's field and in the particular case at hand. Id.

108 See, e.g., L.H. v. R.H., N.Y.L.J., Oct. 6, 1989, at 26, col. 6 (Sup. Ct. 1989), rev'd sub nom. Linda R. v. Richard E., 162 A.D.2d 48, 561 N.Y.S.2d 29 (2d Dept. 1990), discussed in Stephen A. Newman, A tale of two cases: Reflections on psychological and institutional influences on child custody decisions, 34 N.Y.L.S. L. Rev. 661, 673 674 (1989).

109. Aber and Repucci, The limits of mental health expertise in juvenile and family law, 10 Int'l J. L. \& Psychiatry 167 (1987) at 180.

110. David L. Bazelon, Veils, values, and social responsibility, 37 Am. Psychologist 115, 119 (1982). Other reasons for overconfidence also exist. Psychiatrist Alan A. Stone writes: "Whether it is because they themselves want to be helpful witnesses or to beat the lawyers at their own game, or because they have brought their own agendas to the courtroom, psychiatrists all too frequently . . . claim to possess more objective certainty and subjective conviction than they could possibly justify in a clinical context. . . Alan A. Stone, Revisiting the parable: Truth without consequences, 17 Int'I J. L. \& Psychiatry 79 (1994) at 89.

111. Jeffry $H$. Gallet, Judicial management of child sexual abuse cases, 23 Fam. L.Q. 477, 484 (Fall 1989) ("Treatment decisions are frequently made on evidence that would not be admissible in court. . . . Many experts do not understand the difference between the admissibilityof-evidence-in-court standard and the reasonable-basis-for-treatment standard.").

112. G. Dix, Mental health professionals in the legal process: Some problems of psychiatric dominance, 6:1 L. \& Psychol. Rev. (1981) at 15.

113. The Ethical Guidelines of the American Academy of Psychiatry and Law and the Specialty Guidelines for Forensic Psychologists both recognize this dilemma explicitly and discourage such dual relationships where possible.

114. Alan A. Stone, Revisiting the parable: Truth without consequences, 17 Int'l J. L. \& Psychiatry 79, 83 (1994).

115. This does not suggest disregarding the expert, since most witnesses at trials are interested witnesses, but it suggests that some of the usual cautions that apply to nonexpert partisan witnesses should apply as well to experts. 
116. Cf. Ennis \& Litwack, Psychiatry and the presumption of expertise: Flipping coins in the courtroom, 62 Cal. L. Rev. 693, 721 (1974): psychiatrists may be "prone to diagnose mental illness and to perceive symptoms in ambiguous behavior because they are trained in medical school that it is safer to suspect illness and be wrong, than to reject illness and be wrong."

It is also possible that experts can be concerned about balance in their findings. The need to show that they don't always find abuse might lead such experts occasionally to weigh conflicting evidence in a specific case against a finding of child abuse.

117. Aber and Repucci, The limits of mental health expertise in juvenile and family law, 10 Int'l J. L. \& Psychiatry 167, 178 (1987). Accord, Leigh M. Roberts, Some observations on the problems of the forensic psychiatrist, 1965 Wisc. L. Rev. 240, 261 ("By using both impartial and partial experts, it is felt that the most complete mental picture can be developed.").

118. Bennett v. Jeffries, 40 N.Y.2d 543 (1976). 